\title{
Potenciais ganhos da implementação de jardins filtrantes para o reuso de águas cinzas em prédios públicos
}

A água é um recurso indispensável para a sobrevivência de todo ser vivo, por muitos anos tratada como fonte inesgotável. No entanto, o crescimento da população mundial, e o consumo descontrolado de recursos naturais, trouxeram diversos problemas ambientais, em especial a escassez de água potável para uma parcela considerável da população. O reúso de águas servidas ganha cada vez mais importância, tendo em vista um ciclo mais sustentável da água no meio urbano. No Brasil a maior parte das (ETE) tem limitação quanto à remoção de poluentes. O objetivo deste estudo foi apresentar medidas para mitigar os danos ao meio ambiente e conservação dos recursos naturais, com o reaproveitamento da água através da implantação de um Jardim Filtrante no edifício público o Fórum Desembargador Henrique Capitolino em Jaboatão dos Guararapes -PE. Este trabalho configura-se em uma pesquisa de método misto - procedimento de coleta, análise e combinação de técnicas quantitativas e qualitativas e por meio a revisão bibliográfica e científica. Os resultados da pesquisa estão alinhados à contribuição direta com as metas do PLS estabelecidas pelo CNJ contribuindo com os objetivos de desenvolvimento sustentável. Através da reutilização de águas cinzas no prédio com plantas, denominadas de macrófitas, através de novas tecnologias em jardins filtrantes, demonstrou um payback de menos de um ano e com a implantação trazendo vários benefícios ambientais, sociais e econômicos. O perfil socioeconômico ou nível de instrução não mostrou correlação com a preocupação ambiental, sendo assim é importante fazer considerações a necessidade de um investimento em comunicação contínua e mais efetiva referente a questões ambientais com os que fazem parte do Judiciário em Pernambucano.

Palavras-chave: Água; Jardins filtrantes; Edifício público.

\section{Potential gains from the implementation of filtering gardens for the reuse of greywater in public buildings}

\begin{abstract}
Water is an indispensable resource for the survival of every living being, treated for many years as an inexhaustible source. However, the growth of the world population, and the uncontrolled consumption of natural resources, brought several environmental problems, in particular the scarcity of drinking water for a considerable portion of the population. The reuse of wastewater gains more and more importance, in view of a more sustainable cycle of water in the urban environment. In Brazil most of the (ETE) have limitations regarding the removal of pollutants. The objective of this study was to present measures to mitigate the damage to the environment and conservation of natural resources, with the reuse of water through the implantation of a Filtering Garden in the public building of the Desembargador Henrique Capitolino Forum in Jaboatão dos Guararapes - PE. This work is configured in a research of mixed method - procedure of collection, analysis and combination of quantitative and qualitative techniques and through bibliographic means, from the legal literature. The results of the research are in line with the direct contribution to the PLS goals established by the CNJ, contributing to the sustainable development objectives. Through the reuse of gray water in the building with plants, called macrophytes, through new technologies in filtering gardens, demonstrated a payback of less than one year and with the implementation bringing several environmental, social and economic benefits. The socioeconomic profile or level of education did not show a correlation with environmental concern, so it is important to consider the need for investment and more effective communication regarding environmental issues with those who are part of the Judiciary in Pernambucano.
\end{abstract}

Keywords: Water; Filter gardens; Public building.

Topic: Planejamento Urbano

Reviewed anonymously in the process of blind peer.
Received: 03/04/2021

Approved: 26/04/2021
Maísa Maria Oliveira Cavalcanti de Melo (iD Instituto de Tecnologia de Pernambuco, Brasil http://lattes.cnpq.br/6756275506193509 http://orcid.org/0000-0002-6275-6589 maisamelo19@gmail.com

Luiz Filipe Alves Cordeiro (iD

Instituto de Tecnologia de Pernambuco, Brasil http://lattes.cnpq.br/4004156784497834 http://orcid.org/0000-0001-8146-9465 filipecordeiro@gmail.com

\section{Aldo Torres Sales (iD}

Instituto de Tecnologia de Pernambuco, Brasil http://lattes.cnpq.br/9563136339839657 http://orcid.org/0000-0003-2585-3221

aldo@zootecnista.com.br

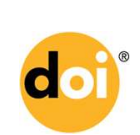

DOI: 10.6008/CBPC2179-6858.2021.004.0060

\section{Referencing this:}

MELO, M. M. O. C.; CORDEIRO, L. F. A.; SALES, A. T.. Potenciais ganhos da implementação de jardins filtrantes para o reuso de águas cinzas em prédios públicos. Revista Ibero Americana de Ciências Ambientais, v.12, n.4, p.796-807, 2021. DOI: http://doi.org/10.6008/CBPC2179-6858.2021.004.0060 


\section{INTRODUÇÃO}

A água, um dos principais recursos naturais do planeta, elemento fundamental para a manutenção da vida e de suma importância para diversas atividades econômicas, tem sua qualidade diminuída ao longo do tempo e, por isso busca-se soluções pautadas no desenvolvimento sustentável para evitar a poluição e a inacessibilidade de água potável (ZORZI et al., 2016).

Segundo a UNESCO (2018), estima-se que em 2050 serão 5,7 bilhões de pessoas que sofrerão com escassez de água devido ao uso irresponsável adotado pela sociedade. Dessa forma, as soluções baseadas em processos naturais são cruciais para o desenvolvimento sustentável, entretanto apesar de terem o potencial de melhorar o desempenho da infraestrutura hídrica construída, são ainda pouco utilizadas. A preocupação com escassez de água e poluição tem aumentado devido à crescente demanda por água, principalmente em países em desenvolvimento, pelo aumento da taxa de consumo de água por habitante e do crescimento da população mundial. Além disso, em locais que possuem deficiências saneamento básico, os corpos hídricos acabam sendo o destino final de diversos contaminantes e poluentes lançados sem qualquer tipo de tratamento (UNESCO, 2018).

O Brasil, apesar de possuir uma grande parte da reserva de água doce mundial, enfrenta alguns desafios, pois enquanto algumas regiões dispõem desse insumo em abundância, outras apresentam escassez. Muitos brasileiros foram afetados por secas ou estiagens entre 2013 e 2016 e, no mesmo período, 47,5\% dos municípios declararam situação de emergência ou estado de calamidade pública, ao menos uma vez, devido a enchentes e inundações (ANA, 2017).

Dessa forma, a conservação desde recurso tão importante é um desafio importante para a sociedade, pois o aumento da população e as várias atividades praticadas pelo ser humano conduzem a um maior consumo de água, reduzindo e as reservas de recursos hídricos.

Diante dessa realidade, ao longo dos anos, buscam-se medidas para o uso mais eficiente da água; entre as principais medidas podemos citar: a redução dos consumos, a redução das perdas e, outra alternativa, o aproveitamento de águas (incluem-se as águas das chuvas, águas do mar, bem com as águas residuais).

Um dos caminhos para o uso mais eficiente é usar a água de melhor qualidade para fins mais nobres e as águas de chuvas, águas cinzas de origem doméstica ou industrial para seu reuso, após sua primeira utilização, dado uma nova finalidade antes de serem destinadas para o esgoto ou galeria pluvial. E para o aproveitamento do reuso de águas ser efetivado necessita de tecnologias apropriadas para o desenvolvimento dessas fontes alternativas, de modo que possam ajudar a suprir a crescente demanda por água, na busca de sustentabilidade e segurança hídrica para as futuras gerações.

Outro fator importante a ser destacado é que a reutilização das águas cinzentas deverá ser sempre realizada in situ e em grandes fontes geradoras de águas cinzentas, como é o caso dos prédios públicos. Por outro lado, ressalta-se que as alterações/adaptações para o reuso com ou sem tratamento colidem na dificuldade de execução e custo, especialmente por esbarrar em diversas legislações voltadas ao setor 
público. Salienta-se também que onde existe possibilidade de grandes avanços e desenvolvimento deste tipo de implementações será sempre na fase de projeto/construção de novos edifícios. O custo-benefício tende largamente para a implementação de sistemas de aproveitamento de águas cinzentas, pois estes tipos de tratamentos têm períodos de retorno, geralmente, em apenas um ano.

Ressalta-se também que novas tecnologias vêm sendo desenvolvidas de forma a reduzir o impacto de lançamentos de efluentes sem tratamento nos corpos hídricos, dentre as diversas tecnologias os sistemas conhecidos como jardim filtrantes, configura-se como uma alternativa viável e de baixo custo que terá um foco específico neste trabalho.

O objetivo principal do estudo foi analisar a viabilidade da implantação de um sistema de tratamento de águas de esgoto com baixo custo em uma edificação pública.

\section{REVISÃO TEÓRICA}

\section{Reuso da Água}

O reuso de águas servidas ganha cada vez mais importância, tendo em vista um ciclo mais sustentável da água no meio urbano. A segregação entre águas escuras (alta concentração matéria orgânica - esgoto sanitário) e águas cinzas (baixa concentração de matéria orgânica) para facilitar o reuso representa um grande avanço.

A reutilização, o reuso de água ou ainda o uso de águas residuárias não é um conceito novo e tem sido praticado em todo o mundo há muitos anos. Existem relatos de sua prática na Grécia Antiga, com a disposição de esgotos e sua utilização na irrigação (CARVALHO et al., 2014), já no extremo Oriente, os dejetos humanos têm sido utilizados há milênios para o cultivo de peixe e plantas aquáticas Hespanhol (2015). O reúso pode ser entendido como o aproveitamento de uma água já utilizada previamente em alguma atividade humana, seja para atender o uso original, seja para atender a uma outra modalidade de uso, o que pode incluir ou não um tratamento prévio (MANCUSO et al., 2003) a seguir na Tabela 1 apresento algumas das formas de reúso.

Tabela 1: Formas de Reúso.

\begin{tabular}{|c|c|}
\hline $\begin{array}{l}\text { Formas de } \\
\text { Reuso }\end{array}$ & Características Gerais \\
\hline Direto & $\begin{array}{l}\text { Uso planejado de esgotos tratados para certa finalidade, tais como: irrigação e água potável. Nada é } \\
\text { descarregado no meio ambiente. }\end{array}$ \\
\hline Indireto & $\begin{array}{l}\text { Quando a água, já utilizada, uma ou várias vezes para o uso do prédio, é descartada nas águas superficiais ou } \\
\text { subterrâneas e utilizada novamente, mas de forma diluída. }\end{array}$ \\
\hline Potável & Com a finalidade de abastecimento da população. \\
\hline Não Potável & Para atender a demanda de qualidade inferior (irrigação, descarga em vasos sanitários, entre outros \\
\hline $\begin{array}{l}\text { Potável } \\
\text { Direto }\end{array}$ & $\begin{array}{l}\text { O esgoto é recuperado porção meio de tratamento avançado e é injetado diretamente no sistema de águas } \\
\text { potável. }\end{array}$ \\
\hline
\end{tabular}

A sustentabilidade de uma cidade só poderá ser atingida com a implementação de medidas como a reutilização e reciclagem - reutilizar significa em primeiro lugar, diminuir o impacto sobre a biosfera dos atuais, de limitar o consumo excessivo e o desperdício, portanto o reúso e aproveitamento fazem parte de uma série de medidas eficientes voltadas para preservação do meio ambiente, da melhoria da qualidade, tais 
práticas levam ao conceito de cidades sustentáveis, entendido como uma simbiose entre os elementos do ambiente natural - água, solo, atmosfera e biodiversidade (BRASIL, 2016).

São denominadas águas cinzas aquelas decorrentes do uso de tanques e máquinas de lavar roupa; chuveiros e lavatórios. Apesar de classificada também como água cinza, águas decorrentes do uso da pia de cozinha, em geral, não são consideradas para fins de reúso, pois contém muita matéria orgânica.

As águas cinzentas representam, em média, $60 \%$ a $70 \%$ do consumo de água potável no interior de uma habitação.

\section{Tecnologias de Reaproveitamento da Água}

Dentre as tecnologias disponíveis para reaproveitamento da água, esse trabalho apresenta as principais características de duas tecnologias que são utilizadas no Brasil e no mundo: a Estação de Tratamento de Esgoto (ETE) e os Jardins Filtrantes.

\section{Estação de Tratamento de Esgoto}

A Estação de Tratamento de Esgoto (ETE) também chamada Estação de Tratamento de Águas Residuais (ETAR) consiste em uma infraestrutura com o objetivo de tratar águas residuais de origem doméstica e/ou industrial, popularmente chamadas de esgotos sanitários, para depois serem destinadas ao rio com um nível de pureza aceitável, conforme legislação vigente.

É importante frisar que as águas residuais (esgotos) passam por vários processos de tratamentos com o objetivo de diminuir a quantidade de impureza. A maior parte das Estações de Tratamentos de Esgotos (ETE) no Brasil tem limitação quanto à remoção de poluentes, principalmente de nitrogênio e fósforo presentes nos esgotos. A maioria das estações de tratamento de água e de esgotos brasileiras foram construídas nas décadas de 1970 e 1980 (LEONETI et al., 2011).

As ETEs tem ganhado cada vez mais espaço devido à escassez hídrica, porém, encontra restrições algumas vezes devido ao gasto com produtos químicos para o tratamento.

\section{Jardim Filtrante}

O sistema conhecido como Jardim Filtrante tem se apresentado como uma ótima alternativa ao tratamento biológico de esgotos. Trata-se de um processo complementar do efluente do tanque séptico (necessário para a quebra de moléculas complexas em moléculas mais simples de fácil absorção pelas raízes das plantas) que são capazes de utilizar a filtração física, química e biológica, na transformação/depuração de poluentes presentes nos esgotos sanitários. Este tipo de sistema possui baixo custo de operação, implantação e manutenção em relação aos sistemas convencionais.

Além disso, este tipo de sistema possui a vantagem de lidar com variações sazonais na emissão de efluentes sem apresentar efeitos adversos ao funcionamento do sistema de tratamento.

Os usos de jardim filtrantes demonstram boas eficiências na remoção de sólidos suspensos, DBO e na concentração de nutrientes (Fósforo e Nitrogênio). Dentro de um sistema jardim filtrante ocorrem 
diversos processos que contribuem para a melhoria da qualidade do efluente, são eles: adsorção de íons amônio e de metais pelos argilominerais, adsorção de íons metálicos, de pesticidas e de compostos a base de fósforo pela matéria orgânica; decomposição da matéria orgânica; decomposição da matéria orgânica biodegradável, tanto aeróbia como anaerobiamente; remoção de patógenos por microrganismos; retiradas de metais pesados e outras substâncias tóxicas (dentro de limites) pelas plantas (macrófitas).

O sistema padrão dos Jardins Filtrantes é composto por três diferentes filtros: Filtro Vertical, Filtro Horizontal e Lagoa Terminal. Os componentes são dimensionados de acordo com as características do efluente tratado. A água que chega à lagoa terminal já estará devidamente tratada e apropriada para banho.

\section{Desenvolvimento Sustentável TJPE}

Os recursos naturais vêm sendo, ao longo do tempo, utilizados com cada vez mais intensidade para corresponder as novas necessidades da vida em meio a uma sociedade moderna. O passar dos séculos trouxe demandas que aparentemente se encaminham para liberar o homem da dependência natural - tecnologia, engenharia, industrialização e migração para a vida no ambiente virtual; entrementes, a aparente superação apenas encobre a transmutação dos recursos extraídos dos solos, mares e subsolos.

Extrai-se desse retrato desenvolvimentista que a dependência da natureza nunca foi tão grande como é hoje. Para atender a essa imensa exploração em uma sociedade de mais de sete bilhões de pessoas que se mantêm a base de consumo - e com expectativa de beirar aos 10 bilhões em 2050, segundo relatório da Organização das Nações Unidas (2019) - o desenvolvimento sustentável é a única forma de manter os recursos necessários à família humana.

Ao tutelar a matéria, a Constituição Federal de 1988 traz o seguinte dispositivo:

Art. 225. Todos têm direito ao meio ambiente ecologicamente equilibrado, bem de uso comum do povo e essencial à sadia qualidade de vida, impondo-se ao Poder Público e à coletividade o dever de defendê-lo e preservá-lo para as presentes e futuras gerações.

\section{Plano de Logística Sustentável}

O Plano de Logística Sustentável do Poder Judiciário (PLS-PJ) foi instituído pela Resolução do CNJ n. 201, de 3 de março de 2015, com a finalidade de implementar a criação de unidades ou núcleos socioambientais nos órgãos e conselhos do Poder Judiciário, e definir competências voltadas para a gestão e o planejamento de ações socioambientais baseadas na aquisição de produtos e serviços que reduzam o impacto ambiental; na prática de ações que promovam as contratações sustentáveis e no desenvolvimento humano para a economia dos recursos naturais e preservação do equilíbrio ambiental.

Entre as metas do PLS e em consonância com o ODS 6 "água e saneamento", o Poder Judiciário Pernambuco deve buscar todas as tecnologias disponíveis para a conservação da água, bem como a mitigação da poluição por falta de saneamento e esgotos não tratados.

Este trabalho configura-se em uma pesquisa de método misto - procedimento de coleta, análise e combinação de técnicas quantitativas e qualitativas em um mesmo desenho de pesquisa. Tomando como referência essa afirmação, delimitou-se este trabalho em duas etapas. A primeira, envolve a realização de 
uma fase qualitativa, com o levantamento de informações e teorias relacionadas ao objeto da pesquisa, por meio bibliográfico, a partir da literatura jurídica em sua maior abrangência, doutrina, legislação, posicionamentos de autoridades e estudiosos nos temas abordados, artigos científicos, sites e periódicos especializados no assunto, para uma maior familiaridade com o conteúdo e aprimoramento de ideias, possibilitando o aprofundamento e a discussão sobre o tema estudado, o que também denota uma pesquisa de caráter exploratório.

A segunda etapa, segue a orientação quantitativa, englobando procedimentos de coleta, validação e análise de dados, com aplicação de pesquisa, tipo survey, que se baseia no interrogatório de usuários/participantes, por meio de perguntas sobre determinadas características, modo de vida, suas intenções, atitudes, comportamentos, percepções e motivações, etc., permitindo a coleta de uma quantidade de informações sobre cada pesquisado de uma vez. Logo, essa pesquisa está voltada para exploração de dados, a partir da aplicação de questionários estruturados e o uso de informações coletadas junto a uma amostra da população alvo. Por fim, é realizado um estudo de caso buscando analisar os potenciais benefícios para o tripé da sustentabilidade com a instalação de um jardim filtrante no Fórum de Jaboatão - Pernambuco.

\section{METODOLOGIA}

Este trabalho configura-se em uma pesquisa de método misto - procedimento de coleta, análise e combinação de técnicas quantitativas e qualitativas em um mesmo desenho de pesquisa. Tomando como referência essa afirmação, delimitou-se este trabalho em duas etapas. A primeira, envolveu a realização de uma fase qualitativa, com o levantamento de informações e teorias relacionadas ao objeto da pesquisa, por meio bibliográfico, a partir da literatura jurídica em sua maior abrangência, doutrina, legislação, posicionamentos de autoridades e estudiosos nos temas abordados, artigos científicos, sites e periódicos especializados no assunto, para uma maior familiaridade com o conteúdo e aprimoramento de ideias, possibilitando o aprofundamento e a discussão sobre o tema estudado, o que também denota uma pesquisa de caráter exploratório.

A segunda etapa, seguiu a orientação quantitativa, englobando procedimentos de coleta, validação e análise de dados, com aplicação de pesquisa, tipo survey, que se baseia no interrogatório de usuários/participantes, por meio de perguntas sobre determinadas características, modo de vida, suas intenções, atitudes, comportamentos, percepções e motivações, etc., permitindo a coleta de uma quantidade de informações sobre cada pesquisado de uma vez. Logo, essa pesquisa está voltada para exploração de dados, a partir da aplicação de questionários estruturados e o uso de informações coletadas junto a uma amostra da população alvo.

Por fim, foi realizado um estudo de caso buscando analisar os potenciais benefícios para o tripé da sustentabilidade com a instalação de um jardim filtrante no Fórum de Jaboatão - Pernambuco. 


\section{Lócus da Pesquisa}

O Prédio denominado de Fórum Desembargador Henrique Capitulino, ocupa uma área de 12.473 m2. Possui estacionamento com 234 vagas no ambiente externo e 35 vagas no setor interno. 0 fórum de atuação do Judiciário no município, que hoje conta com uma população de mais de 700 mil habitantes e que nos últimos anos houve um aumento expressivo da população de Jaboatão e consequentemente das demandas pelos serviços oferecidos pelo Tribunal por um prédio com essa estrutura é fundamental importância para atender com presteza e eficácia ao jurisdicionado local. O município é o décimo mais populoso do Brasil. Neste âmbito, ainda quando falamos do mais populoso, quem lidera a lista é Guarulhos, em São Paulo, com 1,34 milhão de habitantes. Em sequência vem Campinas, também em São Paulo, com 1,8 milhão e São Gonçalo, no Rio de Janeiro, com 1,05 milhão.

É importante destacar que o prédio trabalha em médio 350 (trezentos e cinquenta) funcionários por dia, sendo 280 (duzentos e oitenta) pela manhã e 70 (setenta) no período da tarde. E recebe em média 2000 (dois mil) visitantes por dia.

\section{Avaliação Financeira}

A análise de viabilidade econômica foi medida através do cálculo do Valor Presente Líquido (VPL) também conhecido como Valor Atual Líquido (VAL) e do Tempo de Retorno de Capital (TRC). O VPL é uma fórmula que analisa a série de pagamentos futuros projetados no momento atual. Nesta análise, leva-se em conta os aspectos que diferenciam os projetos e não os aspectos em que os projetos são iguais, isso significa que o diferencial do projeto será traduzido no VPL, e na comparação entre dois projetos, o maior VPL representa o melhor custo benefício.

Essa formulação é ideal, pois leva em consideração o valor do dinheiro com o passar do tempo pois a quantia hoje não será a mesma futuramente devido no mínimo a inflação do país. Logo, a Taxa Mínima de Atratividade é usada para comparar investimentos, ela carrega o significado de no mínimo corrigir o valor do dinheiro devido ao tempo que passa. A formulação do cálculo do VPL é apresentada na Equação 1.

$$
V P L=\sum_{n=0}^{N} \frac{F C_{n}}{(1+T M A)^{n}}
$$

\section{TMA - Taxa Mínima de Atratividade} $\mathrm{n}$ - é a periodicidade da análise.

A interpretação do Valor Presente Líquido se dar inicial e basicamente no sinal de VPL, se positivo o investimento é bom, se negativo, a opção não é viável, em seguida analisar os valores de VPL, logo quanto maior o VPL melhor. Em $\mathrm{n}$ igual a 0 corresponde ao investimento inicial que no caso entra no somatório como negativo.

Por as vez o TRC ou payback simples, resume-se em dividir o valor do investimento pelo valor de economia ou lucro sem considerar o horizonte de tempo logo o dinheiro perde seu valor com o passar do tempo. Essa análise é mais usada em primeira instância pois ela simplesmente esboça um cenário provável o que não a torna tão discrepante do Valor Presente Líquido. A fórmula do Payback simples está escrita na 
Equação 2.

$$
\text { Payback }_{\text {simples }}=\frac{\text { custodoinvestimento }}{\text { economiadevidoaoinvestimento }}
$$

\section{Procedimento de coleta de dados dos questionários}

O método usado foi o misto (qualitativo e quantitativo), com pesquisa bibliográfica, para compor a base teórica, e com pesquisa do tipo survey, para coletar dados e informações a partir de características e opiniões do grupo escolhido, onde o resultado encontrado pode se estender a todo o universo estudado, considerando o grupo que representa determinada população. O survey é bastante utilizado no meio acadêmico, visto que se mostra de grande utilidade para a pesquisa científica, conforme salienta.

Os questionários foram aplicados através da ferramenta Google formulários, contendo 8 questões, no qual, dos 200 servidores envolvidos, 178 configuraram-se como amostra válida, pois responderam efetivamente. Os dados coletados foram tabulados e desses construídos as figuras.

\section{RESULTADOS E DISCUSSÃO}

Previamente caber destacar que até o momento não há a aplicação de práticas sustentáveis voltadas para a redução do consumo de água; há apenas medidas modestas sendo implementadas nos novos fóruns em construção; além disso, foram inauguradas novas unidades judiciais, em razão da crescente demanda judicial, fatores que justificam o crescimento no consumo de água. Diante disso, é necessário que o TJPE adote estratégias de conscientização ambiental visando essa redução junto a todo corpo funcional.

Tabela 2: Consumo Mensal de água do prédio público Fórum Desembargador Henrique Capitulino durante 12 meses.

\begin{tabular}{lll}
\hline Mês/Ano & Consumo/M3 & Valor (R\$) \\
\hline Fevereiro/2019 & 563 & 5310,50 \\
Março/2019 & 536 & 5054,73 \\
Abril/2019 & 461 & 4346,60 \\
Maio/2019 & 391 & 3702,91 \\
Junho/2019 & 435 & 4119,601 \\
Julho/2019 & 488 & 4622,34 \\
Agosto/2019 & 479 & 4518,17 \\
Setembro/2019 & 465 & 4385,17 \\
Outubro/2019 & 453 & 4271,17 \\
Novembro/2019 & 1091 & 10332,17 \\
Dezembro/2019 & 1091 & 10332,17 \\
Janeiro/2020 & 1155 & 10940,17 \\
Fevereiro/2020 & 789 & 7463,17 \\
\hline
\end{tabular}

Após análise de dados, constatou-se que com a construção de prédio anexo ao prédio e funcionamento posterior, observa-se uma elevação considerável no consumo de água. Então, o TJPE com a responsabilidade social de não prejudicar o meio ambiente realiza o uso de serviços de esgotamento de líquidos sanitários, bem como tratamento de líquido sanitário.

Por outro lado, constata-se um gasto de quase $\mathrm{R} \$ 80$ mil reais anuais de esgotamento, o que poderia ser evitado com tecnologias de reuso de água, objetivo deste trabalho. Logo, esse trabalho, após análise de orçamentos de empresas especializadas na tecnologia de ETE e de jardins filtrantes, chegou aos seguintes 
resultados.

Outro ganho ambiental do jardim filtrante quando comparado as estações de tratamento de esgoto, refere-se ao lodo residual. Visto que a matéria orgânica das ETE é considerado passivo ambiental, pois precisa ser separado e depois transportado de caminhão até um aterro devido à elevada presença de produtos químicos. Este transporte gera um custo mensal de matéria orgânica depositada em aterro, o que aumenta o custo total do processo de tratamento de esgotos no caso da ETE.

Analisando os gastos com a conta de água em torno de $\mathrm{R} \$ 120.000,00$ (cento e vinte mil reais) anuais, adicionada ao gasto período de esgotamento de $\mathrm{R} \$ \mathbf{7 5 . 0 0 0}$ (setenta e cinco mil reais) anuais, totalizando quase duzentos mil reais. Com a análise dos orçamentos, percebe-se que o valor médio da instalação do jardim filtrante ficou em torno de $\mathrm{R} \$ 1$ 190.000, 00 (cento e noventa mil reais), enquanto a ETE resultou em um valor médio de R\$ 220.000 (Duzentos e vinte mil reais).

Utilizando-se as equações 1 a 3, o payback para utilização do jardim filtrante, refere-se ao tempo que um investimento leva para pagar o seu investimento inicial. O valor médio calculado para o investimento inicial será de $\mathrm{R} \$ 190.000,00$ (Cento e noventa mil reais) onde a média de retorno mensal será de $\mathrm{R} \$ 16.667$ onde o tempo de retorno é dado pela seguinte maneira: Payback = Investimento Inicial/Ganhos no período; Tempo de retorno $=$ Investimento Inicial/retorno mensal; Tempo de retorno $=190.000,00 / 16.667=11,4$ meses.

Para o cálculo da ETE, o resultado é bem similar: Payback = Investimento Inicial/Ganhos no período; Tempo de retorno $=$ Investimento Inicial/retorno mensal; Tempo de retorno $=220.000,00 / 16.667=13,2$ meses. Ou seja, tanto a ETE como o Jardim Filtrante apresenta um payback rápido de aproximadamente 1 ano de retorno do investimento, o que demonstra a viabilidade do investimento na tecnologia.

Vale ressaltar, que não está sendo levado em consideração o gasto com produtos químicos e manutenções realizadas no atual sistema e nem na ETE, ou seja, a economia pode ser bem maior com a instalação do Jardim Filtrante.

\section{Resultados Sociais}

A percepção dos servidores do tribunal de justiça de Pernambuco quanto ao uso sustentável da água e uma possível implementação de jardins filtrantes nos prédios do TJ são apresentadas nas figuras abaixo.

Na figura 1 é apresentado a idade dos entrevistados, que em média mostrou ser em maiores de 40 anos. Esses resultados corroboram com os apresentados em relatório da Secretaria de Gestão de Pessoas do tribunal de Justiça, o que fortalece os resultados desta pesquisa que pode ser visto na Figura 1, a idade prevalente no local é maior de 40 anos.

Na Figura 2 é apresentado o grau de escolaridade da população entrevistada, cuja maior predominância é a pós graduação que representa a maioria significativa da amostra. Esses resultados explicam a melhor compreensão das políticas públicas, bem como uma melhor conscientização das obrigações como cidadãos na preservação do meio ambiente.

Para as demais perguntas utilizou-se a escala Likert que é um tipo de escala de resposta psicométrica 
usada habitualmente em questionários, e é a escala mais usada em pesquisas de opinião. Ao responderem a um questionário baseado nesta escala, os perguntados especificam seu nível de concordância com uma afirmação.

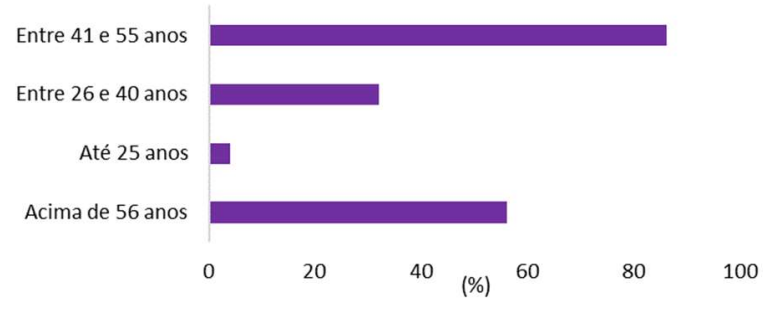

Figura 1: Perfil dos entrevistados quanto a idade.

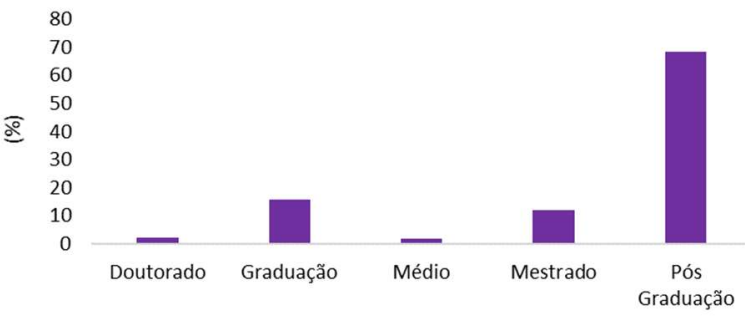

Figura 2: Perfil dos entrevistados quanto grau de instrução.

Mais de 90\% demonstra-se a preocupação com atitudes de preservação ambiental. Chama a atenção que apenas $0,6 \%$ não se preocupa com o tema (Figura 3).

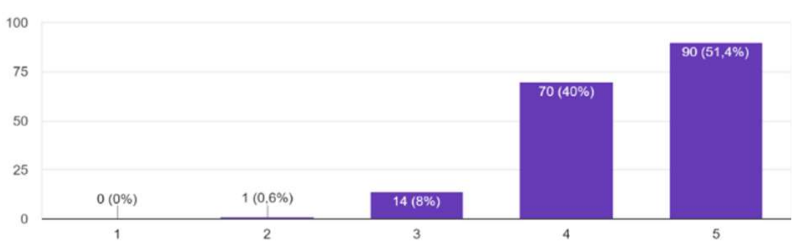

Figura 3: Escala de Likert acerca do senso de preocupação do uso sustentável dos recursos naturais por servidores do tribunal de justiça de Pernambuco.

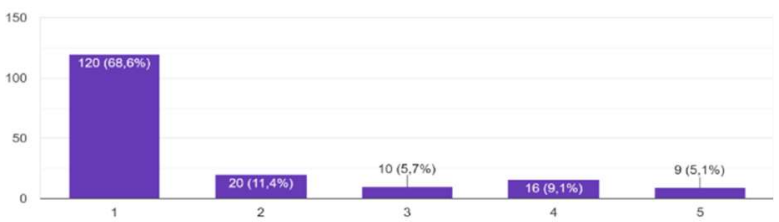

Figura 4: Escala de Likert acerca do senso de preocupação com economia de água no ambiente de trabalho por servidores do tribunal de justiça de Pernambuco.

Uma parcela de quase $15 \%$ concorda que não se preocupam com o gasto de água no ambiente de trabalho (Figura 4). Mesmo sendo pessoas preocupadas com o meio ambiente, por não está diretamente ligado ao pagamento do recurso da água e a preocupação com as atividades profissionais, essa preocupação é diminuída com a conservação da água.

É importante também contrastar com a Figura 5, onde se demonstra que nem sempre o elevado grau de instrução está diretamente ligado as preocupações com as questões ambientais.

Por outro lado, em ambiente residencial em que se influência nas despesas diretas, apenas 3\% não se preocupa com o gasto de água em casa (Figura 5).

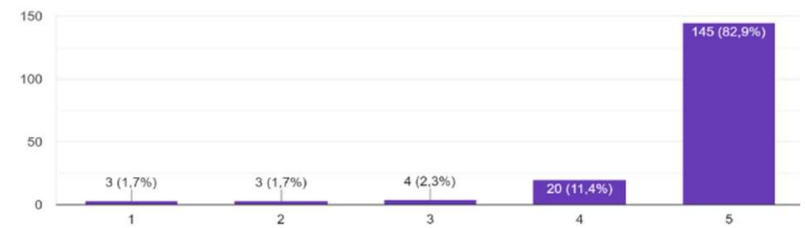

Figura 5: Escala de Likert acerca do senso de preocupação com economia de água em casa por servidores do tribunal de justiça de Pernambuco.

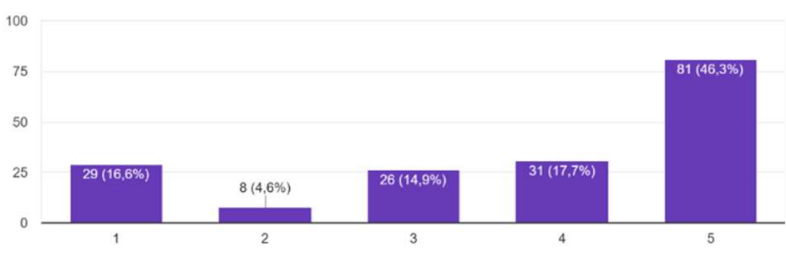

Figura 6: Escala de Likert acerca do conhecimento sobre Jardim Filtrante por servidores do tribunal de justiça de Pernambuco.

A tecnologia jardim filtrante, embora tenha sido responsável pelo tratamento de água de pontos turísticos famosos no mundo inteiro como o Rio Sena e ainda presente em fábricas nacionais famosas ainda é totalmente desconhecida por quase $70 \%$ dos entrevistados que nunca ouviram falar de jardim filtrante 
(Figura 6).

Quando questionados se apoiam a implementação e inciativas nos prédios do TJ que visem a economia de água (Figura 7). Apenas $1 \%$ discorda do investimento em tecnologias voltadas a tecnologias da economia de água. $\mathrm{O}$ que demonstra que é notório que o TJPE deve investir em tecnologias voltadas a economia da água. Da mesma forma, os servidores do TJPE demonstraram-se unânime também que o TJPE deve investir em tecnologias de reaproveitamento de água, pois, apenas 0,6\% discorda do TJPE investir em tecnologias de reaproveitamento de água (Figura 8).

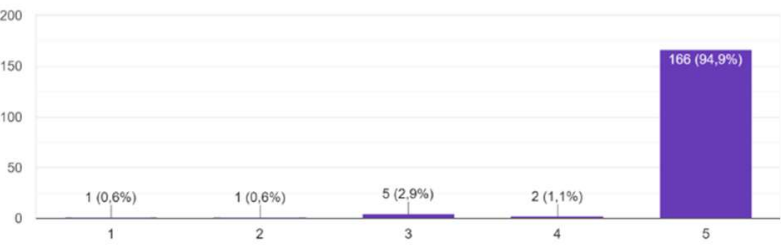

Figura 7: Escala de Likert acerca do posicionamento sobre a necessidade de investimento em tecnologias voltadas a economia de água por servidores do tribunal de justiça de Pernambuco.

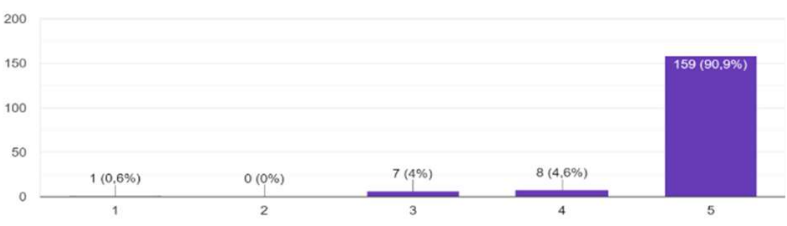

Figura 8: Escala de Likert para a percepção dos servidores do tribunal de justiça de Pernambuco. Sobre a necessidade de investimento em Tecnologias para reaproveitamento de água.

\section{CONCLUSÕES}

Constata-se que o investimento em novas tecnologias, mais especificamente em jardins filtrantes, pode trazer vários benefícios ambientais, econômicos e sociais a gestão de prédios dos tribunais de justiça de Pernambuco. Os resultados do trabalho podem ser levados aos tomadores de decisão para melhor avaliar o reuso da água e contribuir diretamente com as metas do Plano de Logística Sustentável estabelecidas pelo Conselho Nacional de Justiça.

Com este trabalho também foi possível avaliar a percepção dos servidores em que ficou claro que o perfil socioeconômico ou nível de instrução não mostrou correlação com a preocupação ambiental, sendo assim é importante fazer considerações a necessidade de um investimento em comunicação contínua e mais efetiva referente a questões ambientais com os que fazem parte do Judiciário Pernambucano, para uma adoção da prática de racionalização do uso da água e uma política com geração de benefícios a sociedade.

Por fim, os resultados do trabalho estão alinhados à contribuição direta com as metas do Plano de Logística Sustentável estabelecidas pelo Conselho Nacional de Justiça contribuindo com os objetivos de desenvolvimento sustentável. As novas tecnologias em jardins filtrantes, demonstrou um payback de menos de um ano com a implantação trazendo vários benefícios ambientais, sociais e econômicos como os apresentados.

\section{REFERÊNCIAS}

ANA. Agência Nacional de Águas. Conjuntura dos recursos hídricos no Brasil 2017: relatório pleno. Brasília: ANA, 2017.

BRASIL. Políticas públicas para cidades sustentáveis: integração intersetorial, federativa e territorial. Rio de Janeiro: IBAM, 2016

CARVALHO, N. L.; HENTZ, P.; SILVA, J. M.. Reutilização de águas residuarias. Revista Monografias Ambientais-UFSM,

Santa Maria, v.14, n.2, p.3164-3171, 2014. DOI: https://doi.org/10.5902/2236130812585

HESPANHOL, I.. A inexorabilidade do reúso potável direto. Revista Dae, v.63, n.198, 2015. DOI:

http://doi.org/10.4322/dae.2014.141 
LEONETI, A. B.; PRADO, E. L.; OLIVEIRA, S. V. W. B..

Saneamento básico no Brasil: Saneamento básico no Brasil: considerações sobre investimentos e sustentabilidade para o século XXI. Revista de Administração Pública, v.45, n.2, p.331-348, 2011. DOI: https://doi.org/10.1590/S0034$\underline{76122011000200003}$

MANCUSO, P. C. S.; BREGA FILHO, D.. Conceito de reúso de água. In: Reúso de Água. São Paulo: Manole, 2003.
UNESCO. Relatório mundial das Nações Unidas sobre desenvolvimento dos recursos hídricos 2018: soluções baseadas na natureza para a gestão da água, resumo executivo. Brasília: UNESCO, 2018.

ZORZI, L.; TURATTI, L.; MAZZARINO, J. M.. O direito humano de acesso a água potável: uma análise continental baseada nos Fóruns Mundiais da Água. Revista Ambiente e Água, v.11, n.4, p.954-971, 2016. DOI:

http://dx.doi.org/10.4136/ambi-agua.1861

A CBPC - Companhia Brasileira de Produção Científica (CNPJ: 11.221.422/0001-03) detém os direitos materiais desta publicação. Os direitos referem-se à publicação do trabalho em qualquer parte do mundo, incluindo os direitos às renovações, expansões e disseminações da contribuiç̃ão, bem como outros direitos subsidiários. Todos os trabalhos publicados eletronicamente poderão posteriormente ser publicados em coletâneas impressas sob coordenação da Sustenere Publishing, da Companhia Brasileira de Produção Científica e seus parceiros autorizados. Os (as) autores (as) preservam os direitos autorais, mas não têm permissão para a publicação da contribuição em outro meio, impresso ou digital, em português ou em tradução. 